concentration of oxalic acid was also decreased by anodic oxidation using graphite electrode as shown in Fig. 4. Since the contribution of anodic oxidation to oxidative degradation at $E_{B}=1.2 \mathrm{~V}$ was larger than that at $E_{B}=1.7 \mathrm{~V}$, as indicated in the previous paper, ${ }^{3)}$ the electrolysis condition of $E_{B}=1.2$ was found to be effective for complete degradation of phenol.

Figure 5 shows the energy consumption for reducing the COD. Since the bypass current flowed in the electrolyte phase, the energy consumption of a bipolar cell was larger than that of a single cell with a pair of flat electrodes. The energy consumption decreased with increasing oxygen velocity and was minimized to $1 \times 10^{8} \mathrm{~J}$ per $\mathrm{kg}$-COD for the reduction of the COD to $50 \mathrm{ppm}$ under the most suitable condition. The bipolar electrolyzer having a vertical stack of perforated electrodes was found to be effective in scaling up the electrolyzer.

Nomenclature

$C \quad=$ concentration $\quad\left[\mathrm{mol} \cdot \mathrm{m}^{-3}\right]$
$\begin{array}{ll}E & =\text { cell voltage } \\ E_{B} & =\text { difference betw }\end{array}$ cathodic potentiat of

$\begin{array}{lll}\boldsymbol{F} & =\text { Faraday's constant } \quad\left[\mathrm{C} \cdot \mathrm{mol}^{-1}\right]\end{array}$

$I_{f} \quad=$ Faradaic current $\quad[\mathrm{A}]$

$I_{t} \quad=$ total current $\quad[\mathrm{A}]$

$Q \quad=$ total coulombs [C]

$Q_{T} \quad=$ theoretical coulombs defined by Eq. (1) [C]

$u_{G} \quad=$ gas velocity $\left[\mathrm{m} \cdot \mathrm{s}^{-1}\right]$

$V \quad=$ volume of reactant solution $\quad\left[\mathrm{m}^{3}\right]$

$\kappa=$ electrical conductivity of solution $\quad\left[\mathrm{S} \cdot \mathrm{m}^{-1}\right]$

$\langle$ Subseript $\rangle$

$0 \quad=$ initial value

\section{Literature Cited}

1) Fukuda, T.: The 16th Kenkyu Koryu (Research Exchange) Seminar, p. 34 (1982).

2) Hagiwara, K.: PPM, 13(6), 16 (1982).

3) Sudoh, M., T. Kodera, H. Hino and H. Shimamura: $J$. Chem. Eng. Japan, 21, 198 (1988)

4) Sudoh, M., T. Kodera, K. Sakai, J. Q. Zhang and K. Koide: J. Chem. Eng. Japan, 19, 513 (1986).

\title{
A NEW SOLUTION TO THE PROBLEM OF NONISOTHERMAL GAS ABSORPTION IN A PACKED TOWER
}

ISAMI YOSHIFUKU

Department of Chemical Engineering, Kagoshima University, Kagoshima 890

Key Words: Absorption, Packed Tower, Flowgraph, Computer Simulation, Sequential Cell

Solutions to the design problem of nonisothermal packed gas absorber, based on graphical and computational techniques, were well developed by several investigators ${ }^{1-6)}$ during the $1970 \mathrm{~s}$. In these researches, a major effort has been made to establish a model in which the physical property data, the resistance in gas phase and/or liquid phase, and the heat effects e.g. heat of solution, latent heat of vaporization and sensible heat transfer in both phases are of significance.

In this report, a new solution based on flowgraph representation is presented for the purpose of computer simulation of a packed tower process.

\section{Problem Statement}

In the flowgraph construction, the following as-

Received September 21, 1987. Correspondence concerning this article should be addressed to I. Yoshifuku. sumptions are made:

1) adiabatic gas absorption in a packed tower with ammonia-air-water system is treated.

2) liquid-phase resistance to heat and mass transfer are ignored and the influence of solvent evaporation is accounted for.

3) heat of solution, latent heat of vaporization and molar specific heat are constant.

The problem calls for the determination of tower height from the data of tower bottom, tower top, physical properties and volumetric heat and mass transfer coefficients.

\section{Sequential Cell Flowgraph Construction}

An algorithm for the problem of the packed tower process has previously been reported, ${ }^{71}$ along with a detailed procedure of sequential cell flowgraph construction. In brief, the procedure consists of tabu- 
lation of the fundamental equations, transformation of equation to flowgraph unit, formation of the $n$-th cell flowgraph, and construction of a sequential cell flowgraph.

As the first step, the $n$-th cell model of the packed tower and the relevant fundamental equations are shown in Fig. 1 and Table 1, respectively.

The number of equations is $17 N+1$, and the number of variables is $17 N\left(L_{n}, G_{n}, x_{n}, y_{n}, w_{n}, q_{L n}, q_{A n}, q_{W n}\right.$, $\left.q_{G n}, N_{A n}, N_{W n}, y_{S n}, w_{S n}, t_{L n}, t_{G n}, p_{W n}, K_{n}\right)$ and $9\left(L_{N+1}\right.$, $\left.x_{N+1}, t_{L N+1}, G_{0}, y_{0}, w_{0}, t_{G 0}, Z, N\right)$. Known variablesspecific heat, volumetric mass and heat transfer coefficients and so forth-are not counted. Therefore, the number of degrees of freedom is $(17 N+9)-$ $(17 N+1)=8$, which is assigned to $G_{B}\left(=G_{0}\right)$, $L_{T}\left(=L_{N+1}\right), y_{B}\left(=y_{0}\right), w_{B}\left(=w_{0}\right), t_{G B}\left(=t_{G 0}\right), y_{T}\left(=y_{N}\right)$, $x_{T}\left(=x_{N+1}\right)$ and $t_{L T}\left(=t_{L N+1}\right)$.

As the second step, each of the fundamental equations is transformed to the flowgraph unit, which is used to construct the $n$-th cell flowgraph shown in Fig. 2. Note that numbers refer to the relevant equation numbers and there exist tearing variables $q_{G n}, N_{A n}$, $N_{W n}$ on the left-hand side variables column in this flowgraph. Calculation in this flowgraph will be commenced with this left-hand side variables column and must be continued until the convergence inequality is satisfied:

$$
d v 1=d v q_{G}+d v N_{A}+d v N_{W}<\varepsilon
$$

where $\varepsilon$ is a small number (e.g. 0.001) and, for example, $d v q G$ is the deviation of trial-and-error calculation defined as

$$
d v q_{G}=\left|\left(q_{G n}-q_{G n}^{\prime}\right) / q_{G n}\right|
$$

From the fundamental equations the following

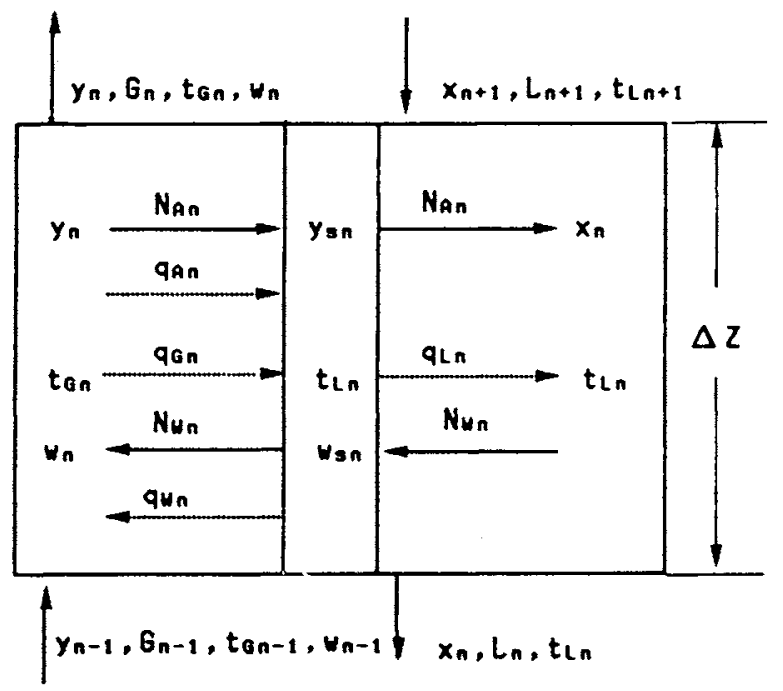

Fig. 1. $n$-th cell model

Table 1. Fundamental equations

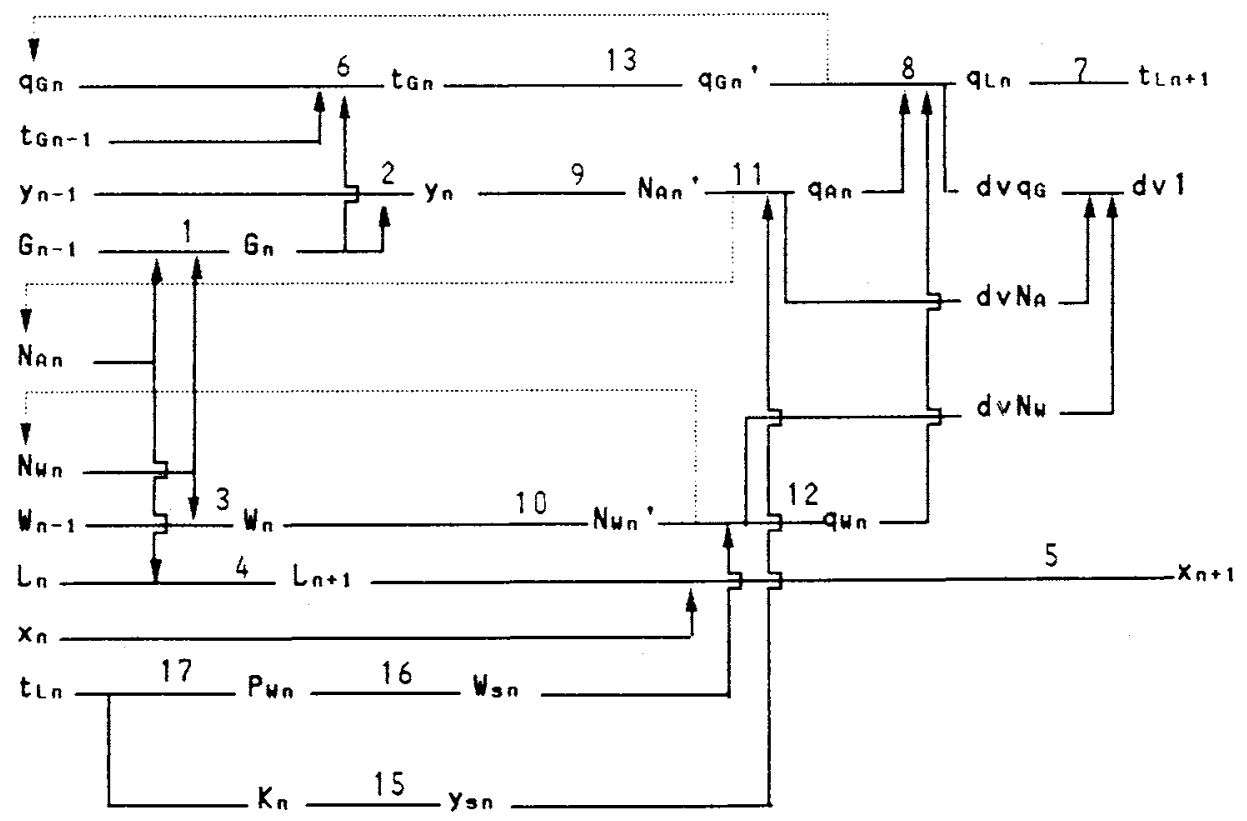

Fig. 2. $n$-th cell flowgraph 


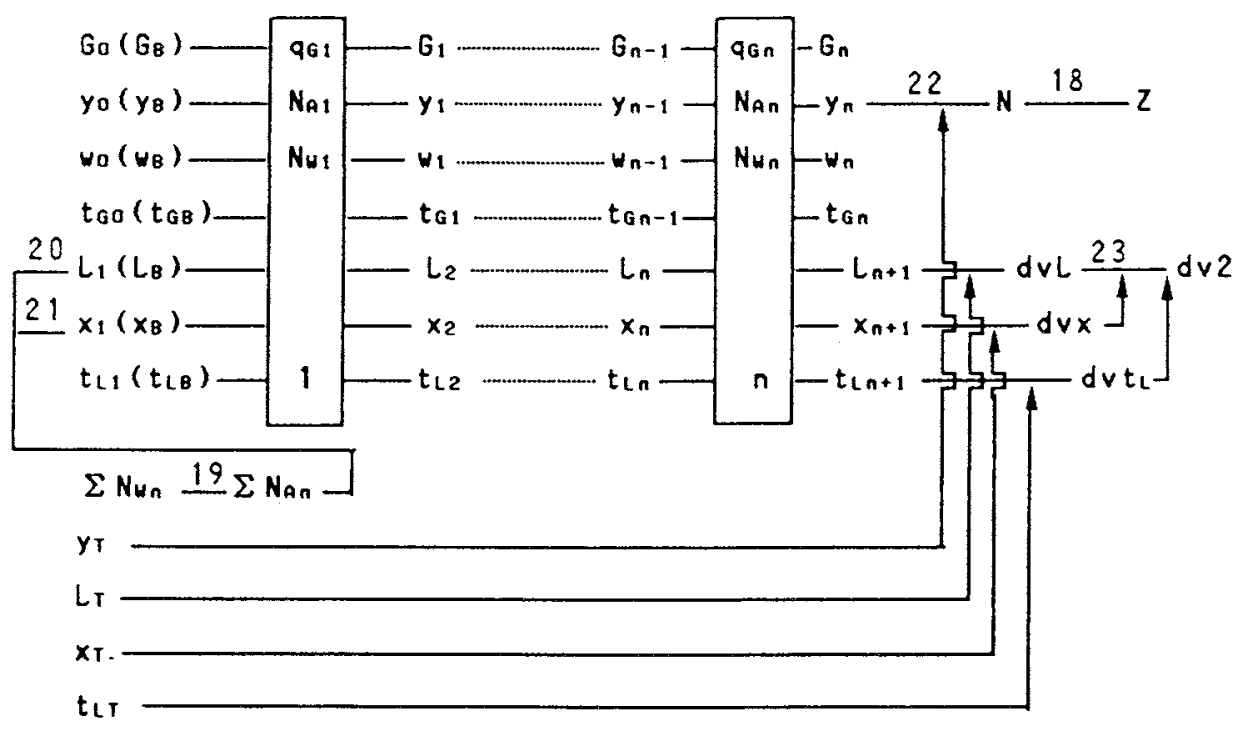

Fig. 3. Sequential cell flowgraph

equations are derived:

$$
\begin{aligned}
\Sigma N_{A n}= & G_{B} \cdot\left(y_{B}-y_{T}\right) /\left(1-y_{T}\right) \\
& -\Sigma N_{W n} \cdot y_{T} /\left(1-y_{T}\right) \\
L_{B}= & L_{T}+\Sigma N_{A n}-\Sigma N_{W n} \\
x_{B}= & \left(x_{T} \cdot L_{T}+\Sigma N_{A n}\right) / L_{B}
\end{aligned}
$$

which show that we can get the values of $\Sigma N_{A n}, L_{B}$, and $x_{B}$ from known variables $G_{B}, y_{B}, y_{T}, L_{T}, x_{T}$ and the unknown variable $\Sigma N_{W n}$. Next, the sequential cell flowgraph, constructed by connecting $n$ cell flowgraphs in order of increasing cell number, is shown in Fig. 3, where the following equations are used.

$$
\begin{aligned}
& N=n: \quad y_{n}<y_{T} \\
& d v 2=d v x+d v t_{L}+d v L
\end{aligned}
$$

Calculation is commenced with the first cell using the variables $G_{B}, y_{B}, w_{B}, t_{G B}, L_{B}, x_{B}$ and appropriate value of $t_{L B}, \Sigma N_{W n}$ and $\Delta Z$ (e.g. 0.01). Cell-by-cell calculation based on the $n$-th cell flowgraph shown in Fig. 2 must be continued until the $N$-determining equation Eq. (22) is reached, and then we can determine the tower height $Z$ by Eq. (18).

Then the sum of deviations $d v 2$ based on Eq. (23) should be calculated, and we can expect a one-to-one correspondence between the value of $d v 2$ and assumed values of $t_{L B}$ and $\Sigma N_{W_{n}}$. The value of $d v 2$ can be expected to be minimum when the values of $t_{L B}$ and $\Sigma N_{W n}$ are selected correctly. Therefore, this cell flowgraph presents a two-variable searching problem:

$$
t_{L B}, \Sigma N_{W_{n}}: \quad d v 2=\min .
$$

\section{Numerical Example}

As an illustrative example, the following case is treated. A gas mixture consisting of ammonia $\left(y_{B}=\right.$
0.05 ), water vapor $\left(w_{B}=0.005\right)$ and air, flowing at the rate of $G_{B}=27.77 \mathrm{~mol} / \mathrm{m}^{2} \cdot \mathrm{s}, t_{G B}=25^{\circ} \mathrm{C}$ and $1 \mathrm{~atm}$, is to be scrubbed $\left(y_{T}=0.0025\right)$ countercurrently with water entering at $x_{T}=0.0, t_{L T}=20.0^{\circ} \mathrm{C}$ and $L_{T}=$ $55.55 \mathrm{~mol} / \mathrm{m}^{2} \cdot \mathrm{s}$ in a packed tower. The problem calls for the determination of the tower height. All physical properties are taken from the literature: ${ }^{2.3)}$ heat of solution and latent heat of vaporization for water, $\lambda_{A}=34643.5$ and $\lambda_{W}=43906.9 \mathrm{~J} / \mathrm{mol}$, volumetric heat and mass transfer coefficients $h_{G} a=1627.1 \mathrm{~W} / \mathrm{m}^{3} \cdot \mathrm{K}$, $k_{y} a=55.55$ and $k_{W} a=58.33 \mathrm{~mol} / \mathrm{m}^{3} \cdot \mathrm{K}$ and molar specific heat of liquid and gas $C_{P L}=75.312, C_{P G}=$ $29.288 \mathrm{~J} / \mathrm{mol} \cdot \mathrm{K}$.

Work is commenced, in the sequential cell flowgraph shown in Fig. 3, with the two-variable $\left(t_{L B}\right.$ and $\Sigma N_{W n}$ ) searching technique for a small value of $\triangle Z$. For example, using the simplex method, we get the values of $t_{L B}$ and $\Sigma N_{W n}$ for $\Delta Z=0.1$ as $25.42^{\circ} \mathrm{C}$ and $0.5572 \mathrm{~mol} / \mathrm{m}^{2} \cdot \mathrm{s}$, respectively, as well as the value of $Z=2.70 \mathrm{~m}$. This value depends on the value of $\Delta Z$ and we obtain the limited value $Z=2.29 \mathrm{~m}$ when $\Delta Z$ approaches zero. This value is lower than the value obtained by Kunugita $(Z=2.35 \mathrm{~m})$, and we think that this discrepancy is due to the difference in calculation technique. As for the temperature and concentration profiles of gas and liquid through the tower, almost the same results as in the literature $^{2)}$ have been obtained for small values of $\Delta Z$.

A simple model of the system based on that of Kunugita is treated in this paper to show the flowgraph representation. In the same way we can construct the flowgraph for a model where the mass and heat transfer resistance of the liquid phase are accounted for, and the tower height calculation will be made using data of volumetric heat and mass transfer coefficients in the liquid phase. 


\section{Acknowledgment}

The author is grateful to Prof. M. Matsubara of Daido Inst. of Tech. for his guidance and to Mr. Shunichi Nagasato and Mr. Tomoo Yamashita for their assistance during the calculation work.

\begin{tabular}{|c|c|c|}
\hline \multicolumn{2}{|c|}{ Nomenclature } & \\
\hline$C_{P}$ & $=$ & molar heat capacity \\
\hline$d v$ & $=$ & deviation \\
\hline$G$ & $=$ & gas molar velocity \\
\hline$h_{G^{a}}$ & $=$ & $\begin{array}{l}\text { volumetric heat transfer coefficient } \\
\text { (gas phase) }\end{array}$ \\
\hline$h_{L} a$ & $=$ & $\begin{array}{l}\text { volumetric heat transfer coefficient } \\
\text { (liquid phase) }\end{array}$ \\
\hline$K$ & $=$ & equilibrium ratio \\
\hline$k_{W} a$ & & $\begin{array}{l}\text { volumetric mass transfer coefficient } \\
\text { (solvent vapor in gas phase) }\end{array}$ \\
\hline$k_{x} a$ & $=$ & $\begin{array}{l}\text { volumetric mass transfer coefficient } \\
\text { (solute in liquid phase) }\end{array}$ \\
\hline$k_{y} a$ & & $\begin{array}{l}\text { volumetric mass transfer coefficient } \\
\text { (solute in gas phase) }\end{array}$ \\
\hline$L$ & $=$ & liquid molar velocity \\
\hline$N$ & $=$ & total number of cells \\
\hline$N$ & $=$ & mass transfer rate \\
\hline$P$ & $=$ & total pressure \\
\hline$p$ & $=$ & partial pressure \\
\hline$q$ & & heat transfer rate \\
\hline$t$ & $=$ & temperature \\
\hline$x$ & & concentration of solute in liquid \\
\hline$y$ & & concentration of solute in gas \\
\hline
\end{tabular}

$\left[\mathrm{mol} / \mathrm{m}^{3} \cdot \mathrm{s}\right]$

$\left[\mathrm{mol} / \mathrm{m}^{2} \cdot \mathrm{s}\right]$

$\left[\mathrm{mol} / \mathrm{m}^{2} \cdot \mathrm{s}\right]$

[Pa]

$[\mathrm{Pa}]$

$\left[\mathrm{W} / \mathrm{m}^{2}\right]$

[mol/mol]

[mol/mol] $\begin{array}{llr}w & =\text { concentration of solvent in gas } & {[\mathrm{mol} / \mathrm{mol}]} \\ Z & =\text { tower height } & {[\mathrm{m}]} \\ \lambda_{A} & =\text { heat of solution } & {[\mathrm{J} / \mathrm{mol}]} \\ \lambda_{W} & =\text { latent heat of vaporization } & {[\mathrm{J} / \mathrm{mol}]} \\ \Delta Z & =\text { height of cell } & {[\mathrm{m}]}\end{array}$

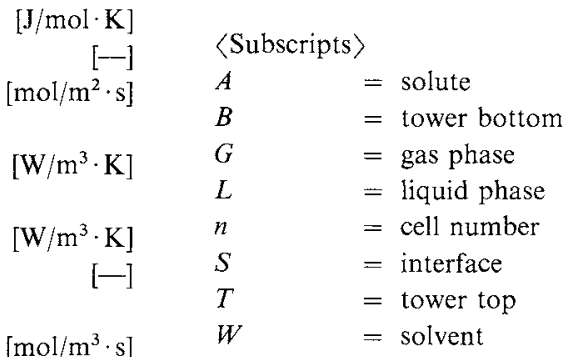

$\left[\mathrm{mol} / \mathrm{m}^{3} \cdot \mathrm{s}\right] \quad$ Literature Cited

1) Inazumi, H., T. Suzuki and S. Yamaguchi: Kagaku Kōgaku, 36, 768 (1972).

2) Kagaku Kogaku Kyokai: "Kagaku Kogaku Benran, 4th Ed.," p. 509, Maruzen, Tokyo (1978).

3) Kunugita, E.: Kagaku Kōgaku, 27, 900 (1963).

4) Raal, J. D. and M. K. Khuroma: Can. J. Chem. Eng., 51, 162 (1973).

5) Stocker, U. V. and Wilke, R.: Ind. Eng. Chem., Fundam., 16, $88(1977)$.

6) Treybal, R. E.: Ind. Eng. Chem., 61, 36 (1969).

7) Yoshifuku, I.: J. Chem. Eng. Japan, 18, 137 (1985).

\section{FUZZY CONTROL OF BLOOD PRESSURE BY DRUG INFUSION}

YOSHIYUKI YAMASHITA AND MUTSUMI SUZUKI

Department of Chemical Engineering, Tohoku University, Sendai 980

KOICHI KAMBE

Department of Urology, School of Medicine, Tohoku University, Sendai 980

Key Words: Process Control, Fuzzy Control, Blood Pressure, Biomedical Engineering, Hypertensive

Chemotherapy

\section{Introduction}

It is necessary to control the arterial blood pressure in many clinical situations. Hypertensive crisis, postoperative recovery and induced-hypertensive chemotherapy are examples of such cases. In an actual clinical situation, blood pressure is often difficult to control even by experienced doctors. Several approaches toward automated blood pressure controllers have been reported. ${ }^{1,2.3)}$ It is pointed out that the

Received December 28, 1987. Correspondence concerning this article should be addressed to Y. Yamashita. action of some controllers does not always match the judgment of doctors.

In this work, the control operation of a skilled doctor was emulated as a preliminary approach. Fuzzy control was applied to the automatic control of blood pressure by hypertensive drug infusion. The main characteristic of this method is that the controller action is very close to human judgment. The fuzzy controller used in this work was originally developed for the control of packed bed reactors. ${ }^{4)}$ Almost the same algorithm could be used for the present case with a little modification. 